\title{
Resolution of Complete Atrioventricular Block in a Patient with Severe Hypothyroidism
}

\section{Said $\mathrm{S}^{1}$, Cooper $\mathrm{CJ}^{1}$ and Hernandez $\mathrm{GT}^{*_{1}}$}

${ }^{1}$ Department of Internal Medicine, Paul L. Foster School of Medicine, Texas Tech University Health Sciences Center, United States

${ }^{*}$ Corresponding author: Hernandez GT. MD, FASN, FACP, Department of Internal Medicine, Paul L. Foster School of Medicine, Texas Tech University Health Sciences Center, 4800 Alberta Avenue, El Paso, Texas, USA 79905; Fax: 915-545-6634, Tel: 915-443-5505, E-mail: german.hernandez@ttuhsc.edu

Citation: Said S, Cooper CJ, Hernandez GT (2013) Resolution of Complete Atrioventricular Block in a Patient with Severe Hypothyroidism. J Case Rep Stud 1(3): 301. doi: 10.15744/2348-9820.1.301

Received Date: November 21, 2013 Accepted Date: December 21, 2013 Published Date: December 24, 2013

\section{Introduction}

Causes for syncope are multifaceted. Hormonal etiology, specifically hypothyroidism, is associated with cardiac arrhythmias [1]. Sinus bradycardia, low voltage, nonspecific T-wave changes and dissociative atrioventricular (AV) abnormalities are some of descriptive electrocardiographic features [2]. In the majority of well know clinical presentations complete AV block requires the insertion of a permanent pacemaker. However hypothyroidism related bradycardia and consequential symptomatic AV blocks could be reversible with timely and proper management.

We report a case of severe hypothyroidism resulting in insertion of transient pacemaker with favorable clinical course and fully reversible complete AV block after accordant pharmacological hormonal substitution.

\section{Case report}

Fifty-two year-old female patient without significant past medical history presented to the emergency room accompanied by her family with syncope. The patient at this time was unable to provide detailed history. According to her family social history and family history were unremarkable. Her husband reported that during the breakfast she suddenly fell from the chair on the floor without preceding symptoms and lost her consciousness for about 2 minutes. He initially tried to perform the Heimlich maneuver because he thought her symptoms are related to chocking from the breakfast. After regaining her consciousness she couldn't remember what happened. Apart from this occasion she reported feeling tired, generalized weakness, cold intolerance and noticed being increasingly depressive within the last 2-3 months. Similar syncope episodes were not observed.

Her vital signs revealed low heart rate of 22/ min was noticed, normal blood pressure $123 / 72 \mathrm{mmHg}$ and normal temperature $36.1^{\circ} \mathrm{C}$. She had a puffy face and slow speech; examination of the neck revealed no struma. Cardiovascular exam demonstrated regular heart sounds without murmur and bruits. The jugular venous pressure was normal. The electrocardiogram demonstrated complete AV block and bradycardia with minimum heart rate of $22 /$ min (Figure 1 ). The chest $x$-ray showed mild pulmonary edema. Laboratory findings revealed severe hypothyroidism with a thyroid-stimulating hormone (TSH) of $>100 \mathrm{mlU} / \mathrm{L}$, free T4 of $1.3 \mathrm{pmol} / \mathrm{l}$ (normal range 9-24), and mild anemia (hemoglobin of $10.1 \mathrm{~g} / \mathrm{dL}$ ). Antithyroid peroxidase antibodies (anti-TPO) and thyrotropin receptor antibodies (TSH receptor antibodies) were negative. Comprehensive metabolic panel was remarkable for elevated transaminases (Table 1).

\begin{tabular}{|c|c|}
\hline \multicolumn{2}{|c|}{ Initial laboratory Work up } \\
\hline White blood cell count & $10.05 \times 10^{3} \mathrm{uL}$ \\
\hline Hemoglobin & $10.1 \mathrm{~g} / \mathrm{dL}$ \\
\hline Hematocrit & $33.4 \%$ \\
\hline Platelet count & $233 \times 10^{3} \mathrm{uL}$ \\
\hline Sodium & $139 \mathrm{mmol} / \mathrm{L}$ \\
\hline Potassium & $4.1 \mathrm{mmol} / \mathrm{L}$ \\
\hline Serum glucose & $117 \mathrm{mg} / \mathrm{dL}$ \\
\hline Bilirubin & $2.3 \mathrm{mg} / \mathrm{dL}$ \\
\hline AST & $121 \mathrm{unit} / \mathrm{L}$ \\
\hline ALT & $134 \mathrm{unit} / \mathrm{L}$ \\
\hline Alkaline phosphatase & $98 \mathrm{unit} / \mathrm{L}$ \\
\hline TSH & $>100 \mathrm{mlU} / \mathrm{L}$ \\
\hline Free T 4 & $1.3 \mathrm{pmol} / \mathrm{L}$ \\
\hline
\end{tabular}

Table 1: Laboratory workup at admission

A temporary pacemaker was inserted with a basal ventricular rate of 60 beats per minute (Figure 2). She was treated with intravenous levothyroxine with a loading dose of $100 \mathrm{mcg}$ followed by orally daily dose of $25 \mathrm{mcg}$. Transthoracic echocardiography showed normal left ventricular systolic 


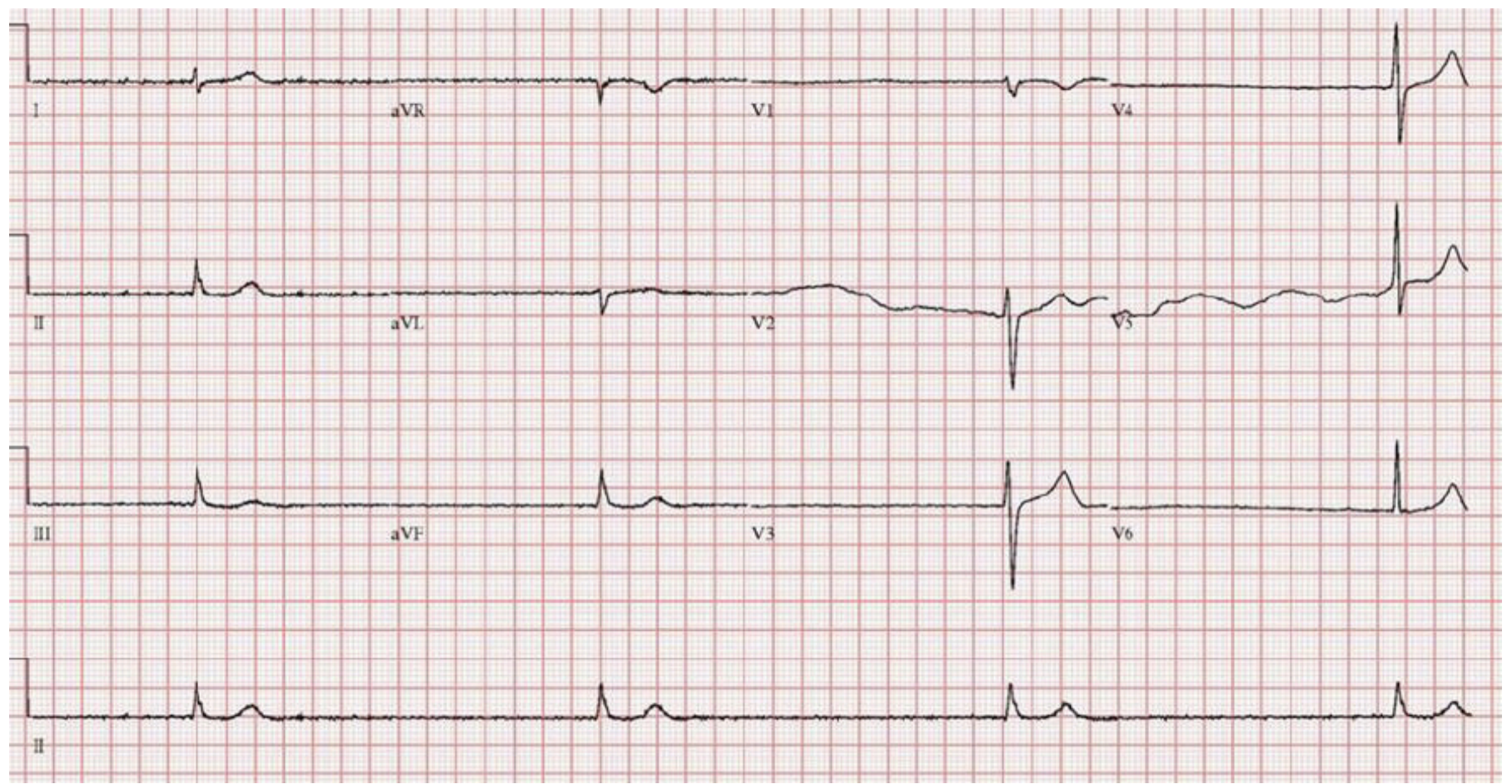

Figure 1: ECG at admission demonstrates bradycardic rhythm (heart rate of 22 beats per minute), without signs of ischemic changes

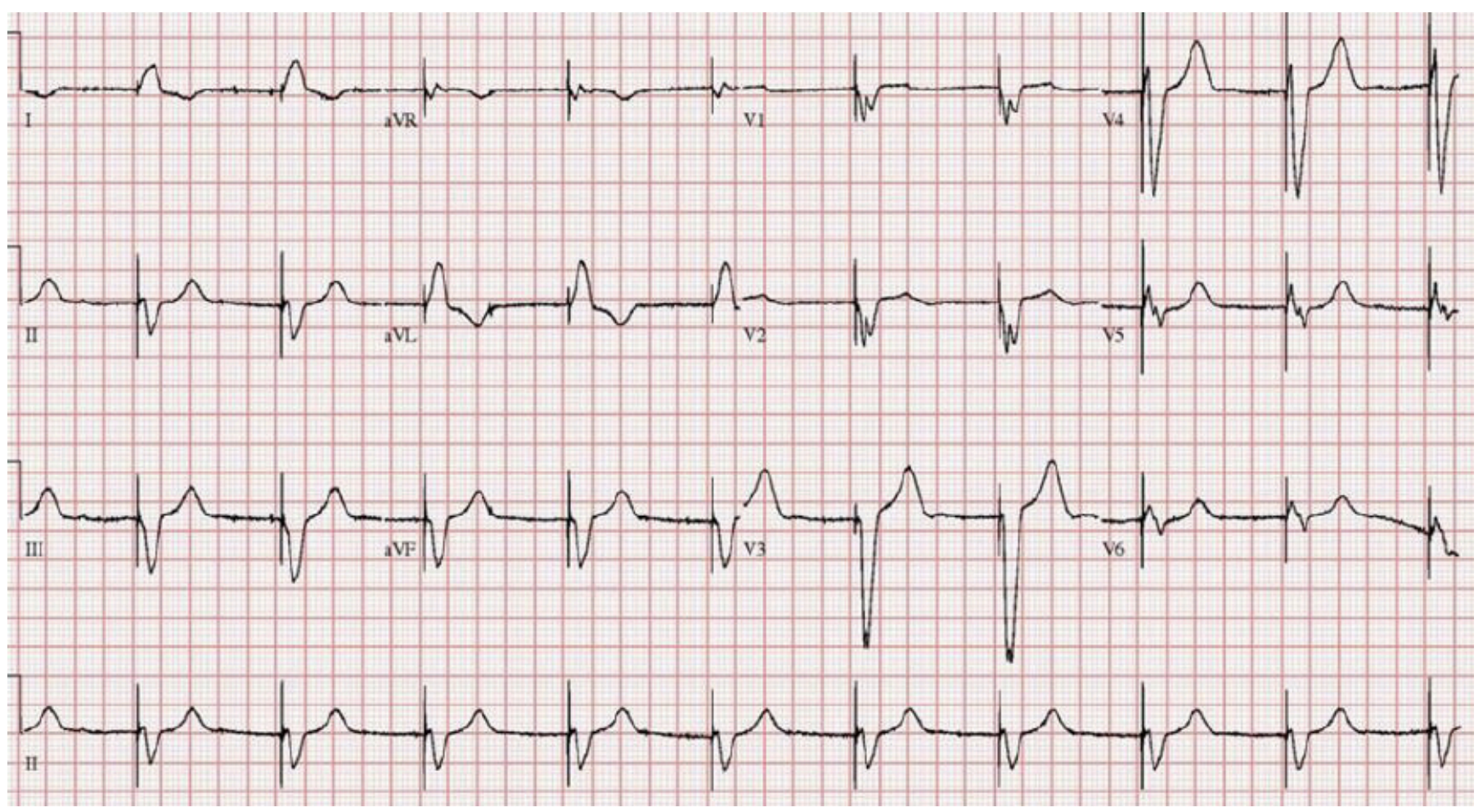

Figure 2: ECG after insertion of transient pacemaker

function with grade I diastolic dysfunction and mild mitral vale regurgitation. Coronary angiography was not significant for local lesions.

Four days after initiating the treatment the AV conduction was restored and the ECG showed sinus rhythm $47 / \mathrm{min}$, the external pacemaker was removed. She was discharged home on the seventh day. Five weeks after her initial presentation the ECG revealed full recovery (Figure 3), the TSH level decreased to $27.3 \mathrm{mlU} / \mathrm{L}$ and the $\mathrm{T} 4$ level was within normal limit.

\section{Discussion}

Hypothyroidism can lead to reduction in oxygen utilization in all major organs leading to cardiac oxygen mismatch. Decline in cardiac output as well as cardiac contraction, bradycardia, increased risk of atherosclerosis, and incremental development of cardiac resistance are just some of anticipated pathophysiologic cardiovascular changes [1]. Permanent symptomatic cardiovascular dysfunction is less common in 


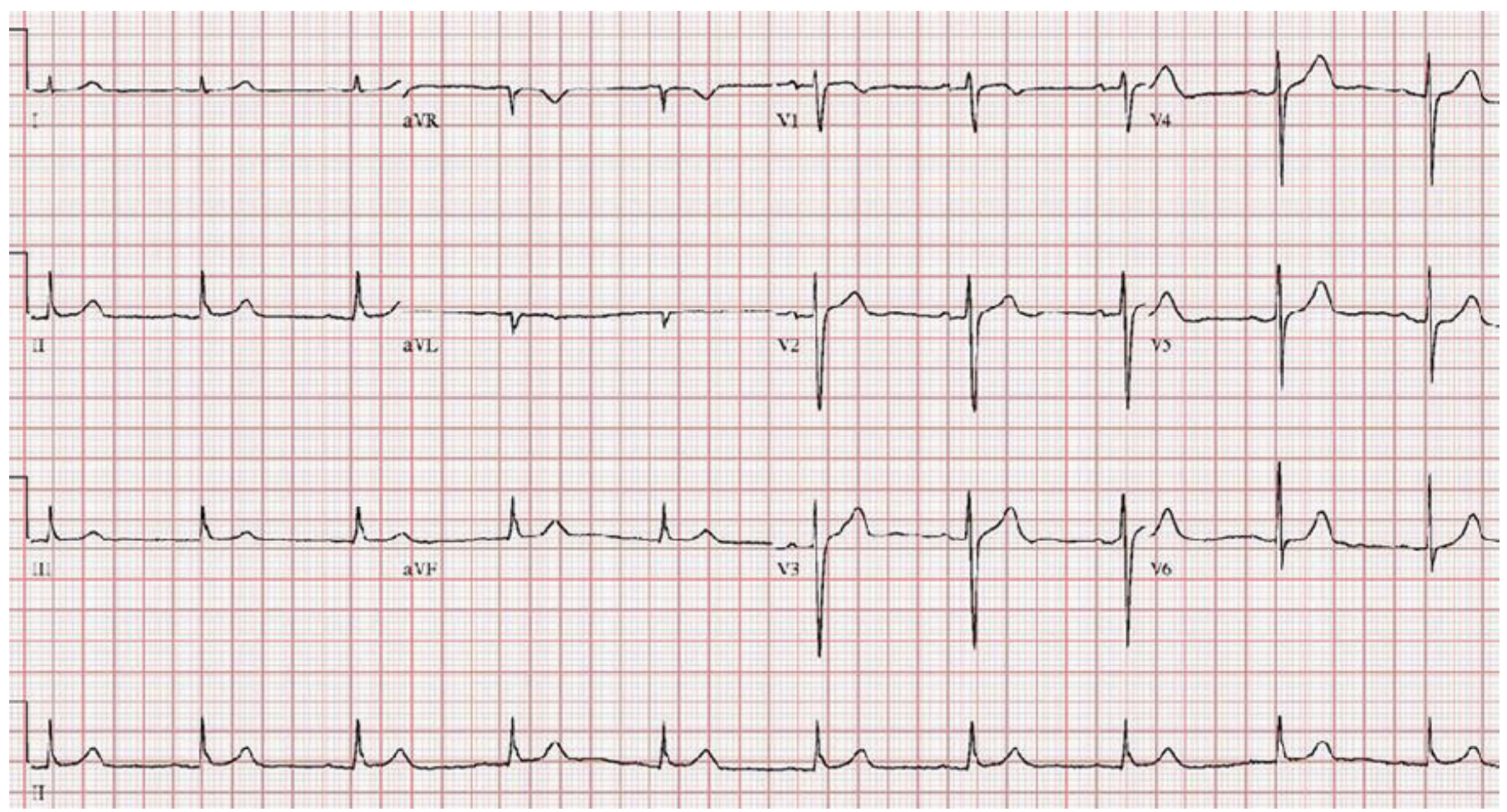

Figure 3: ECG after complete resolution of the high grade AV-block demonstrating regular sinus rhythm.

the setting of hypothyroidism. Common symptoms include shortness of breath, cold intolerance and generalized weakness.

Clinical presentation of hypothyroidism are associated with bradycardia, syncope, nonpitting edeme or symptoms related to pleural and/or pericardial effusion [3]. Atrioventricular blocks and subsequently resulting ventricular tachycardia were observed in the setting of severe hypothyroidism [4]. The exact pathophysiologic cardiac conduction abnormality remains unclear. Histopathologic features of the myocardium may represent interstitial edema, fibrotic changes and mucinous vacuolization $[5,6]$.

Following initiation of hormonal therapy (thyroxine) recessional electrocardiographic abnormalities are rapidly observed. Hypothyroidism is one of the rare bradicardiogenic etiologies, which can show complete recovery under pharmacological management. Few cases have been reported in the literature demonstrating favorable course with complete resolution of the atrioventricular conduction abnormality [710]. However extensive myocardial fibrotic changes can lead to irreversible conduction delay. Affected patients fail to improve despite proper thyroid hormone treatment [2].

About 4.6 percent of the U.S. population age 12 and older has hypothyroidism [11]. The clinical course in elderly population may be perfidiously.

The numerous and constant relationships and feedback mechanisms between the liver and all endocrine organs is reflected by the fact that an alteration of one oftentimes results in the malfunction of the other. Hypo and hyperthyroidism are frequently associated with hepatic alterations as in our patient. Typically these changes resolve with treating the underlying cause [12].

\section{Conclusion}

Hypothyroidism is often underestimated in elderly patients. Therefore accurate evaluation of the thyroid function is recommended before implanting a permanent pacemaker in all patients with delayed atrioventricular conduction, specifically in elderly patients. Hormonal replacement (thyroxine) in the setting of hypothyroidism should be the implemental approach. This case report demonstrates a full recovery of high degree AV-block to normal sinus rhythm in severe hypothyroidism following hormone replacement.

\section{References}

1. Klein I, Danzi S (2007) Thyroid disease and the heart. Circula $\neg$ tion 116: 1725-35.

2. Sepehrdad R, Paulsen J, Amsterdam EA (2012) The ECG that came in from the cold. Am J Med 125: 246-8.

3. Kota SK, Meher LK, Krishna S, Modi K (2012) Hypothyroidism in metabolic syndrome. Indian J Endocrinol Metab 16(Suppl 2): S332-3.

4. Purtell K, Roepke TK, Abbott GW ( 2010) Cardiac arrhythmia and thyroid dysfunction: a novel genetic link. Int J Biochem Cell Biol 42: 1767-70.

5. Okabe M, Kubara K, Kawaguchi H, Kawano T, Nakashima Y, et al. (1990) A case of myxedema with diffuse myocardial fibrosis proven by endomyocardial biopsy. Kokyu To Junkan 38: 1159-63.

6. Pearse GS, Dahdal DM, Grocott-Mason R, Dubrey WS (2011) Myxoedematous pre-coma and heart failure. Br J Hosp Med (Lond) 72: 52-3. 7. Singh JB, Starobin OE, Guerrant RL, Manders EK (1973) Reversible atrioventricular block in myxedema. Chest 63: 582-5.

8. Nakayama Y, Ohno M, Yonemura S, Uozumi H, Ko $\neg$ bayakawa N, et al. (2006) A case of transient 2:1 atrioventricular block, resolved by thy $\neg$ roxine supplementation for subclinical hypothyroidism. Pacing Clin Electrophysiol 29: 106-8.

9. Schantz ET, Dubbs AW (1951) Complete auriculoventricular block in myxedema with reversion to normal sinus rhythm on thyroid therapy. Am Heart J 41:613-9. 
10. Schoenmakers N, de Graaff WE, Peters RH (2008) Hypothyroidism as the cause of atrioventricular block in an elderly patient. Neth Heart J 16: 57-9.

11. Golden SH, Robinson KA, Saldanha I, Anton B, Ladenson PW (2009)

Prevalence and incidence of endocrine and metabolic disorders in the United

States: a comprehensive review. J Clin Endocrinol Metab 94: 1853-78.
12. Burra P (2013) Liver abnormalities and endocrine diseases. Best Pract Res Clin Gastroenterol 27: 553-63.

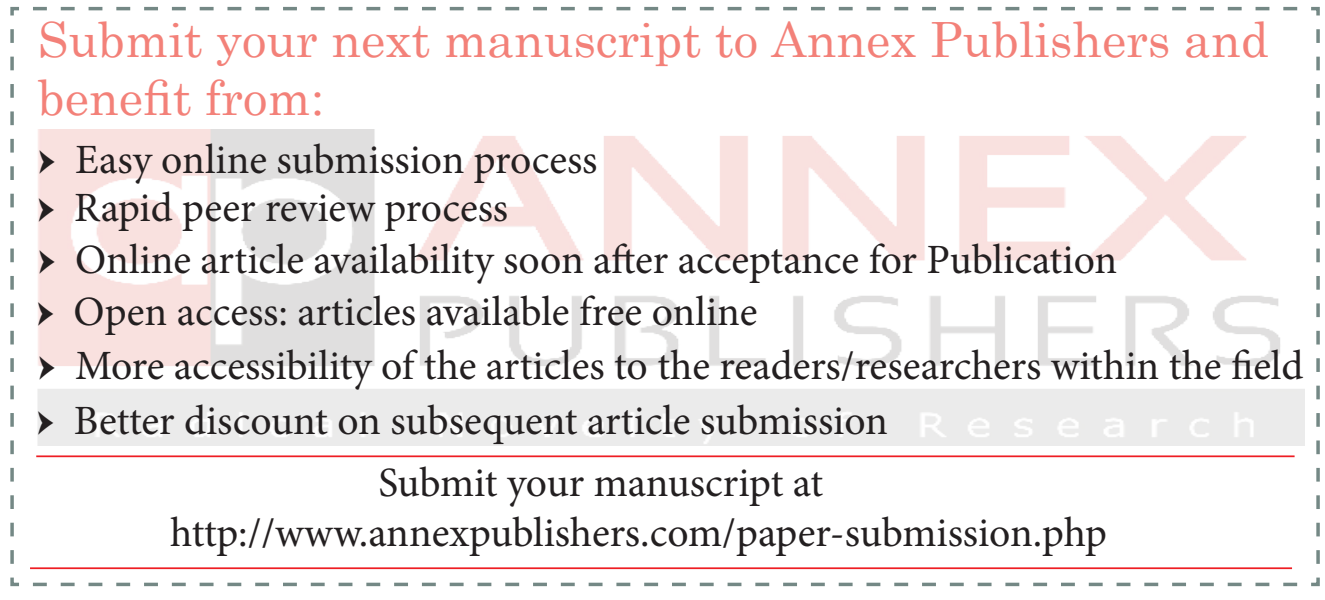

